\title{
Preparation and characterization of porous carbon from expanded graphite for high energy density supercapacitor in aqueous electrolyte
}

\author{
F. Barzegar, A. Bello, D. Y. Momodu, M. J. Madito, J. K. Dangbegnon, and N. Manyala* \\ Department of Physics, Institute of Applied Materials, SARCHI Chair in Carbon Technology and Materials, University \\ of Pretoria, Pretoria 0028, South Africa. \\ Corresponding Author: *Email address: ncholu.manyala@up.ac.za (N. Manyala) \\ Tel: +27 (0)12420 3549, Fax: +27 (0)124202516
}

\begin{abstract}
In this work, we present the synthesis of low cost carbon nanosheets derived from expanded graphite dispersed in Polyvinylpyrrolidone, subsequently activated in $\mathrm{KOH}$ and finally carbonized in Ar atmosphere. Interconnected sheet-like structure with low concentration of oxygen (9.0 at.\%) and a specific surface area of $457 \mathrm{~m}^{2} \mathrm{~g}^{-1}$ was obtained. The electrochemical characterization of the carbon material as supercapacitor electrode in a 2-electrode configuration shows high specific capacitance of $337 \mathrm{~F} \mathrm{~g}^{-1}$ at a current density of $0.5 \mathrm{~A} \mathrm{~g}^{-1}$ as well as high energy density of $37.9 \mathrm{Wh} \mathrm{kg}^{-1}$ at a power density of $450 \mathrm{~W} \mathrm{~kg}^{-1}$.This electrical double layer capacitor electrode also exhibits excellent stability after floating test for $120 \mathrm{~h}$ in $6 \mathrm{M} \mathrm{KOH}$ aqueous electrolyte. These results suggest that this activated expanded graphite (AEG) material has great potential for high performance electrode in energy storage applications.
\end{abstract}

KEYWORDS: Porous carbon; supercapacitor; energy storage; activated carbon nanosheets 


\section{Introduction}

The energy industry is currently facing a global crisis due to the rising cost associated with the high energy demand, a growing population and serious depletion of fossils fuels which raises some environmental issue such as global warming. Thus, there is an urgent need to explore alternative renewable energy resources as well as storage devices with high power and energy densities. In other words, the alternative energy sources are expected to be clean, low cost, environmentally friendly and sustainable [1-3]. Furthermore, new technology has to be implemented for the storage of the energy that can be released during high demand and at any time. In the search for high energy density and high power density energy storage devices, electrochemical technologies demonstrate the aptitude to provide the means for electrical energy storage. Amongst the various electrochemical energy storage devices, supercapacitors have drawn much interest due to their extremely high power density, good cycling stability and fast charge-discharge rate compared to conventional capacitors and lithium-ion batteries which possess a low power density and a short cycle life [4-6]. However, the relatively low energy density of supercapacitors has not yet met the requirements of electrical systems, ranging from portable electronics to hybrid electric vehicles $[7,8]$. Hence, all research efforts are geared towards improving on the energy density of supercapacitors without sacrificing their high power density and high cyclability. Generally, supercapacitors can be classified into two categories according to their different energy storage mechanisms: Electrical double-layer capacitors (EDLCs) and pseudocapacitors (RuO and $\mathrm{MnO}$ ) [4,9]. EDLCs energy storage mechanism is based on electrical double layer charge accumulation at the interface between the electrode and electrolyte. Advances in the field of EDLCs research have shown that the high 
electrochemical performance of these devices is highly dependent on the development of active electrode materials and also on the electrolyte used. In other words, materials with high micropore volume and good representation of the pore structure are needed to improve on the energy density. Carbon-based materials with high specific surface area (SSA) have been widely studied as electrode materials for EDLCS owing to their good electrochemical performances which include reasonably high specific capacitance and long-term cyclability, excellent physicochemical properties, high electrical conductivity. In addition, their synthesis is generally easy and cost effective. While activated carbon is the material of choice for commercial supercapacitors, other forms of carbon materials such as carbide-derived carbons (CDCs) [10], onion-like carbons (OLCs) [11], carbon nanotubes (CNTs) [12] and graphene [13] are currently being considered as next generation EDLC electrodes. In general, the electrochemical performance of carbon based EDLC device is highly dependent on its SSA, pore size and pore size distribution (PSD) [14]. Therefore, it is necessary to control these parameters during the production of the carbon materials. This is usually done through physical activation using steam or $\mathrm{CO}_{2}$ on one hand or through the traditional chemical activation using activating agents such as $\mathrm{KOH}, \mathrm{ZnCl}_{2}$, and $\mathrm{H}_{3} \mathrm{PO}_{4}$, on the other hand. Recently, highly porous carbon nanosheets made from a three-dimensional graphene/polymer-based hydrogel with exceptional properties was reported by Zhang et. al. [15]. The Hydrogel was activated with $\mathrm{KOH}$ and the porous materials produced demonstrated a superior supercapacitor performance in ionic liquid. Since the report of Zhang et. al., several other reports based on similar method for production of porous carbons have since been published [16-19]. Herein we explore a two-step synthesis of highly porous carbon using Polyvinylpyrrolidone (PVP) and expanded graphite (EG) as carbon 
precursors. The choice of PVP is based on its ability to disperse and exfoliate carbon material such as graphite [20]. The obtained carbon with unique interconnected sheet-like morphology designated as AEG which stands for activated expanded graphite, exhibits high specific surface

area $\left(457 \mathrm{~m}^{2} \mathrm{~g}^{-1}\right)$ and specific capacitance $\left(337 \mathrm{~F} \mathrm{~g}^{-1}\right)$. High energy density value of $37.9 \mathrm{Wh} \mathrm{kg}^{-1}$ at a power density of $450 \mathrm{~W} \mathrm{~kg}^{-1}$ was obtained. These excellent electrochemical performances were attributed to the unique porous and interconnected morphology of the carbon nanosheets which could facilitate a fast charge transport mechanism.

\section{Experimental}

Scheme 1 presents the preparation process of the AEG material. Firstly, graphite sample (grade ES 250 B5 from Qingdao Kropfmuehi Graphite) was expanded using a microwave oven at an irradiation power of $300 \mathrm{~W}$ for 5 minutes. $1 \mathrm{~g}$ of the expanded graphite (EG) was dispersed in $100 \mathrm{ml}$ of $10 \mathrm{wt} . \%$ Polyvinylpyrrolidone (PVP) and the mixture was sonicated for $12 \mathrm{~h} .5 \mathrm{~g}$ of $\mathrm{KOH}$ was then added to the solution, and the mixture was further stirred for $2 \mathrm{~h}$ at $60{ }^{\circ} \mathrm{C}$. This procedure allows the formation of an EG hydrogel. The obtained EG hydrogel was collected and dried at $70{ }^{\circ} \mathrm{C}$ for $12 \mathrm{~h}$. The dried hydrogel was then placed in a horizontal tube furnace which was ramped from room temperature to $800{ }^{\circ} \mathrm{C}$ at $5{ }^{\circ} \mathrm{C} /$ minute under argon and hydrogen gas flow and kept at this temperature for $2 \mathrm{~h}$ of carbonization. This procedure transforms the EG hydrogel into flakes of carbon material denoted as activated expanded graphite (AEG). The black powder obtained was washed with $1 \mathrm{M} \mathrm{HCl}$ to remove the remaining $\mathrm{KOH}$ and subsequently with deionized water and dried at $60^{\circ} \mathrm{C}$. 


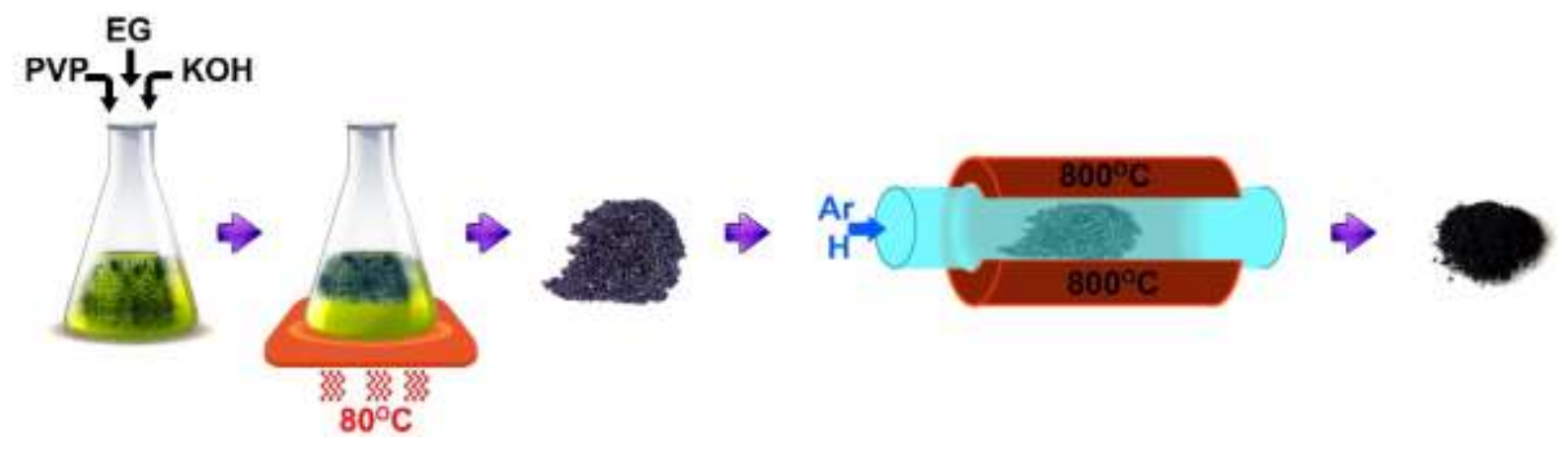

Scheme 1. Schematic diagram of the preparation process of AEG

\section{Structural and electrochemical characterization}

The morphology of the samples was studied using a Zeiss Ultra Plus 55 field emission scanning electron microscope (FE-SEM) operated at an accelerating voltage of $2.0 \mathrm{kV}$. Transmission electron microscopy (TEM) analysis was performed at $200 \mathrm{kV}$ on a JEOL JEM-2100F microscope with field-emission gun. TEM samples were prepared by dispersing the samples in ethanol and which were dropped on a lacey carbon grid. X-ray diffraction (XRD) was recorded using an XPERT-PRO diffractometer (PANalytical BV, the Netherlands) with theta/theta geometry. Qualitative phase analysis of samples was conducted using the X'pert Highscore search match software at room temperature. Raman spectroscopy analysis of the sample was performed using a T64000 micro-Raman spectrometer from HORIBA Scientific equipped with a triple monochromator system to eliminate contributions from the Rayleigh line. All the samples were excited with a $514 \mathrm{~nm}$ line of an Ar laser with a power of $12 \mathrm{~mW}$ to avoid any thermal effect. Nitrogen adsorption-desorption isotherms were measured at $-196{ }^{\circ} \mathrm{C}$ using a Micromeritics TriStar II 3020 (version 2.00) analyzer. All the samples were degassed at $180{ }^{\circ} \mathrm{C}$ for more than $12 \mathrm{~h}$ under high vacuum condition. The surface area was calculated with the Brunauer-Emmett- 
Teller (BET) method from the adsorption branch in the relative pressure range $\left(\mathrm{P} / \mathrm{P}_{0}\right)$ of 0.01 0.2. X-ray photoelectron spectroscopy (XPS) was used to determine the chemistry of the carbon sample. A Physical Electronics VersaProbe 5000 instrument was used which employs a $100 \mu \mathrm{m}$ monochromatic Al-Ka to irradiate the sample surface. Photoelectrons were collected by a $180^{\circ}$ hemispherical electron energy analyzer. Samples were analyzed at a $45^{\circ}$ angle between the sample surface and the path to the analyzer. Survey spectra were taken at pulse energy of $117.5 \mathrm{eV}$, with a step size of $0.1 \mathrm{eV}$, which was used to obtain the elemental analysis of the powders. High-resolution spectra of C1s, N1s, and O1s regions were taken at pulse energy of $23.5 \mathrm{eV}$, with a step size of $0.05 \mathrm{eV}$. All binding energies were referenced to that of the binding energy of C-C at $284.7 \mathrm{eV}$. Peak fitting for the high-resolution spectra was performed using CasaXPS Version 2.3.16 RP 1.6. Prior to the peak fitting the background contribution was subtracted using a Shirley function. The preparation of electrodes was done by mixing the active materials and Polytetrafluoroethylene (PTFE) as a binder with a weight ratio of 90:10, which was homogenized and dispersed in N-methylpyrrolidone (NMP) solution. The resulting paste was then uniformly coated on a nickel foam current collector and dried at $60{ }^{\circ} \mathrm{C}$ in an oven for $8 \mathrm{~h}$ to ensure complete evaporation of the NMP. The electrochemical test of the symmetric cell was carried out in a two electrode cell configuration in a coin cells with a thickness of $0.2 \mathrm{~mm}$ and a diameter of $16 \mathrm{~mm}$. A glass microfiber filter paper was used as separator and the electrolyte was $6 \mathrm{M} \mathrm{KOH}$. All electrochemical measurements were carried out using a Bio-logic VMP-300 potentiostat 


\section{Results and discussion}

Typical morphology and microstructure of the AEG sample were characterized by scanning electron microscopy (SEM) and transmission electron microscopy (TEM). Figure 1 (a) and (b) show low and high magnification SEM of the AEG sample, respectively. The sample displays a network of interconnected sheet-like material. TEM images in Figure 1 (c) and (d) also reveal a unique morphology with a well-developed porous mesh or porous graphene-like flakes. This type of interconnected porous nanosheets would provide a unique open pore system with high active surface area and a short diffusion path for electrolyte ions. Such structure promises to be
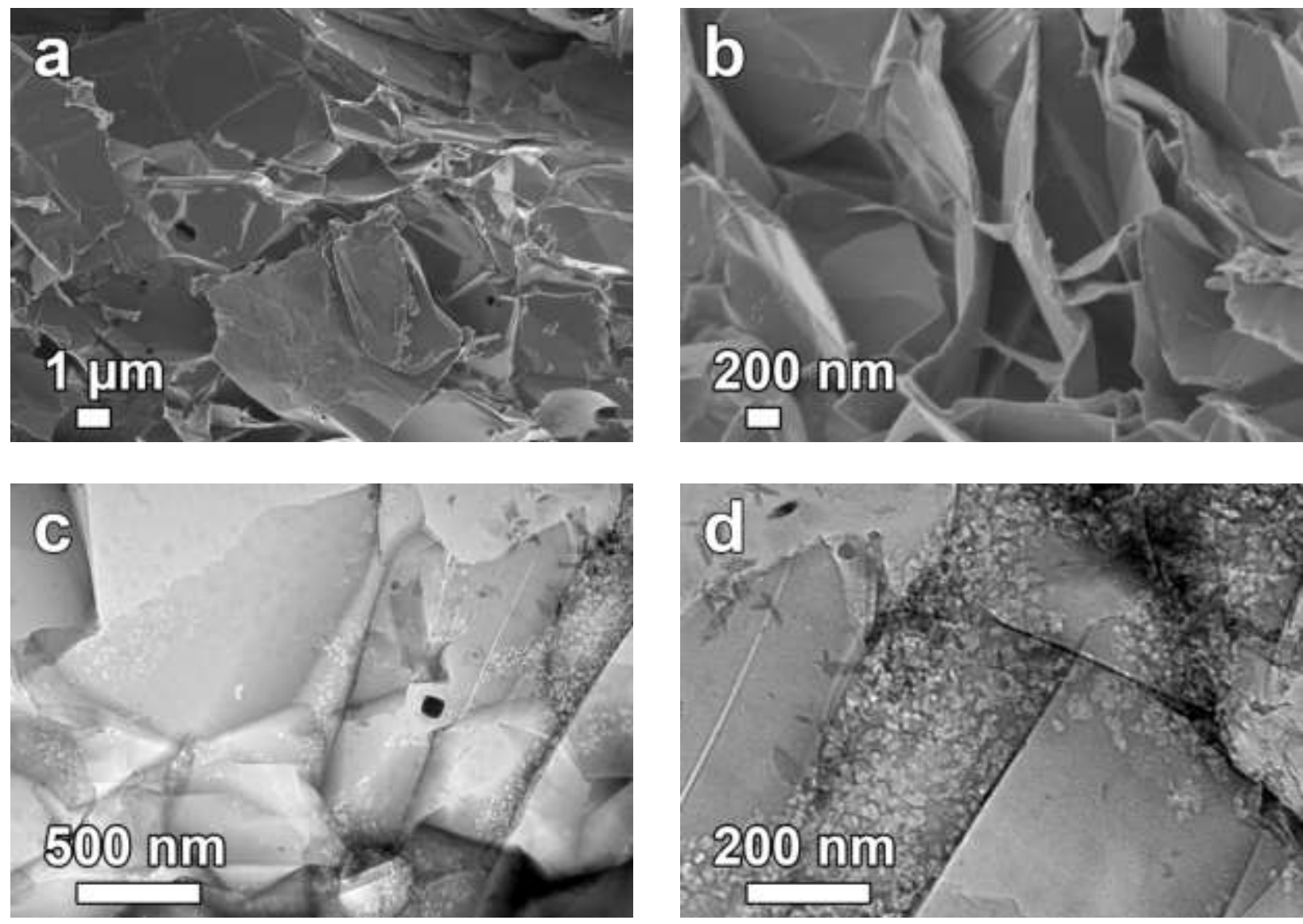

Figure 1 low and high magnification (a) and (b) SEM images and (c) and (d) TEM images of AEG 
a good electrode material for improved electrochemical performance for energy storage applications.

a

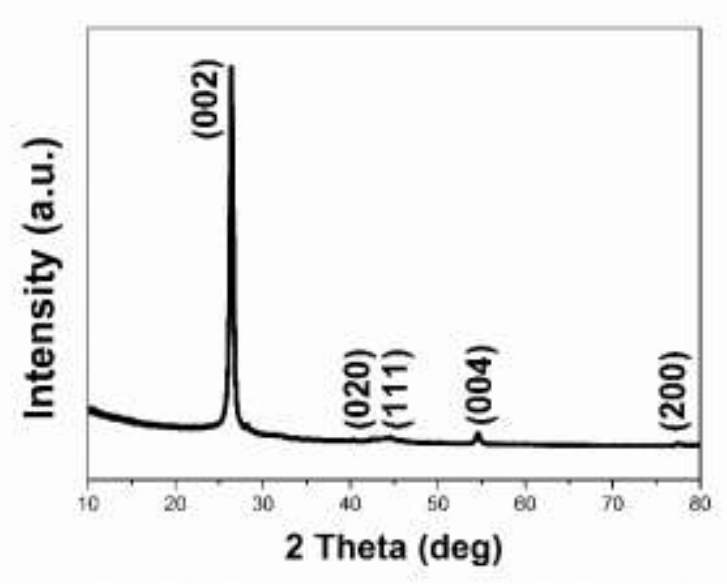

C

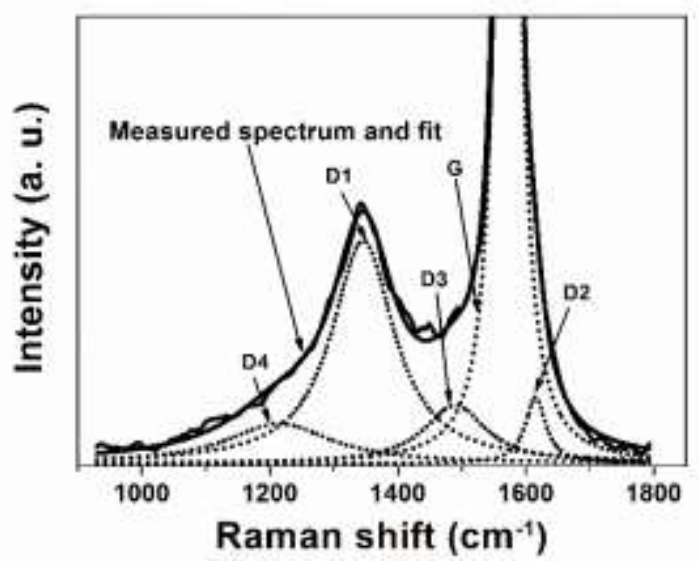

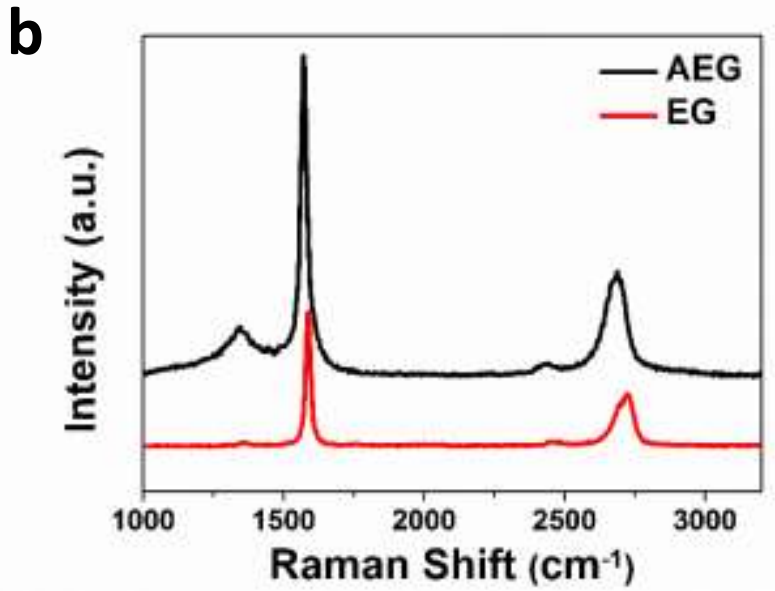

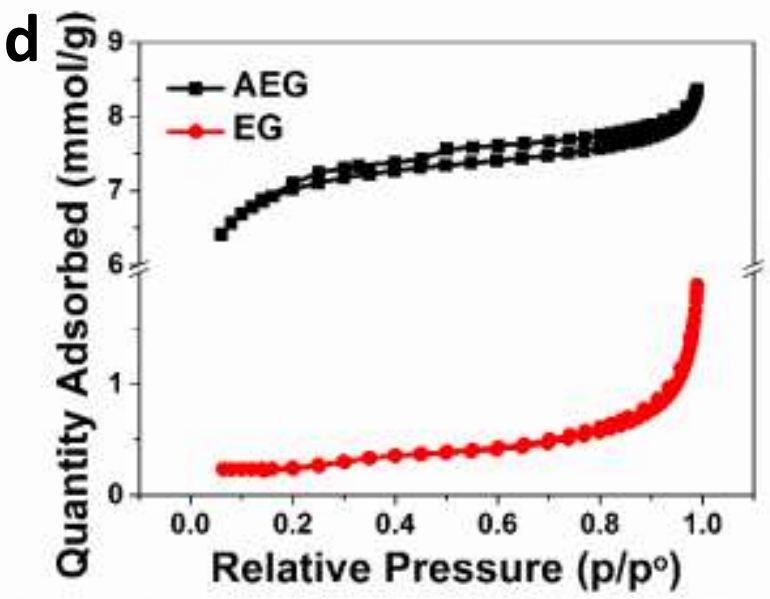

Figure 2 (a) The X-ray diffraction pattern,(b) Raman spectra, (c) Curve fitting (Lorentzians) of different combinations of $D$ and $G$ Raman bands and (d) The $N_{2}$ adsorption-desorption isotherms of the EG and AEG as indicated in the figure.

X-ray powder diffraction (XRD) was used to analyze the crystallinity after carbonization. Figure 2 (a) represents the XRD patterns for AEG powders. It is noted that all the XRD peaks are indexed to graphite peaks (COD: 96-900-0047) exhibiting orthorhombic structure with a space group 
Fmmm(69), with the following lattice parameters: $a=2.4560 \AA, b=4.2540 \AA$ and $c=6.6960 \AA$. The XRD confirms that the material produced is indeed carbon.

In figure 2 (b), EG Raman spectrum shows characteristic of an undisturbed graphitic structure with only the first-order band ( $G$ band) and second order 2D band visible. Such spectrum is commonly observed in highly oriented polycrystalline graphite (HOPG) [20]. On the other hand, the spectrum of the AEG shows additional first-order band ( $D$ band), which is the Raman fingerprint of disorder in the graphitic structure. This broad band can be deconvoluted in 4 bands using a curve fitting with Lorentzian distribution (figure 2(c)). The D1 band has been suggested to arise from the carbon atoms at the edge of a graphene layer and also from the edge planes perpendicular to the graphene layers of large single crystals graphite and HOPG [21]. The D2 band origin is related to the lattice vibration corresponding to that of the $G$ band but involving graphene layers at the surface of graphite which are not directly incorporated between two other graphene layers [22]. The D3 band is known to originate from the distribution of amorphous carbon in interstitial sites in the disturbed graphitic lattice $[23,24]$. The D4 band is related to lattice vibrations corresponding to $s p^{2}-s p^{3}$ bonds $[25,26]$. In brief, Raman spectra suggest that the AEG, compared to EG, consists of a significant fraction of nonintercalated graphene layers and some amount of interstitial amorphous carbon in the lattice structure. The Raman curve fitting presented in Figure 2 agrees well with Raman data reported for other carbonaceous material (e.g. soot) [27]. The porous texture of the two samples was analyzed by $\mathrm{N}_{2}$ physisorption. The nitrogen adsorption-desorption isotherms of AEG curves are shown in Figure 2 (d), and the porous properties of the EG and AEG are listed in Table 1. AEG sample shows a type-II isotherms (definition by IUPAC) with $\mathrm{H} 4$ hysteresis loop in the range of 
ca. 0.20-0.99 $\mathrm{P} / \mathrm{P}_{0}$, suggesting the presence of micropores and mesopores whereas the EG sample shows a type III isotherm with H3 hysteresis loop, suggesting non-rigid aggregates of plate-like structure As observed from table 1, there is a drastic increase in the micropore volume after activation and carbonization of EG material. Furthermore, high concentration of mesopores with smaller diameters was observed for AEG as compared to EG. Moreover, the surface area of the EG material after activation significantly increased from $20 \mathrm{~m}^{2} \mathrm{~g}^{-1}$ to $457 \mathrm{~m}^{2}$ $\mathrm{g}^{-1}$ which corresponds to an increase of over two orders of magnitude.

Table 1 Surface area, micropore and cumulative volume and pore size of AEG

\begin{tabular}{|l|l|l|l|l|}
\hline Sample name & $\begin{array}{l}\text { Surface area } \\
\left(\mathrm{m}^{2} / \mathrm{g}\right)\end{array}$ & $\begin{array}{l}\text { micropore volume } \\
\left(\mathrm{cm}^{3} / \mathrm{g}\right)\end{array}$ & $\begin{array}{l}\text { cumulative volume }^{\mathrm{b}} \\
\left(\mathrm{cm}^{3} / \mathrm{g}\right)\end{array}$ & Pore diameter $^{\mathrm{c}}(\mathrm{nm})$ \\
\hline EG & 20 & 0.004 & 0.066 & 11.23 \\
\hline AEG & 457 & 0.174 & 0.076 & 4.053 \\
\hline
\end{tabular}

${ }^{\mathrm{a}}$ t-Plot micropore volume

${ }^{b}$ BJH Desorption cumulative volume of pores between $1.7000 \mathrm{~nm}$ and $300.0000 \mathrm{~nm}$ diameter

${ }^{c}$ BJH Desorption average pore diameter (4V/A)

The elemental composition of the AEG was obtained from XPS characterization. The results of the peak fit of the high resolution spectra of $\mathrm{C}, \mathrm{N}$, and $\mathrm{O}$ are shown in Figure 3 and summarized in Table 2. The $C$ 1s region (Figure 3 (a)) was fitted by four components corresponding to graphitic carbon, hydrocarbons $\left(\mathrm{CH}_{\mathrm{x}}\right)$, alcoholic (C-O-) and/or carbon nitrogen structures (C-N-) and carboxyl or ester (COO) [28]. The N 1s (Figure 3 (b)) at $400 \mathrm{eV}$ [29] was fitted by two components corresponding to pyrindine/amine (P/A) and/or Nitrile/Pyrrole (N/P). The ratio of P/A to N/P ranges from 2 to 8 . Finally, the $O 1$ s region (Figure 3 (c)) was fitted with only one component corresponding to C-O. From the survey spectra (see table 2), carbon is the main 
element in the sample, followed by oxygen. Also, the sample can be considered doped with nitrogen owning to the small amount of nitrogen in this sample ( 0.5 at.\%). Furthermore, about 0.6 at.\% of Si which is believed to originate from the quartz tube during carbonization is also present in the AEG sample.
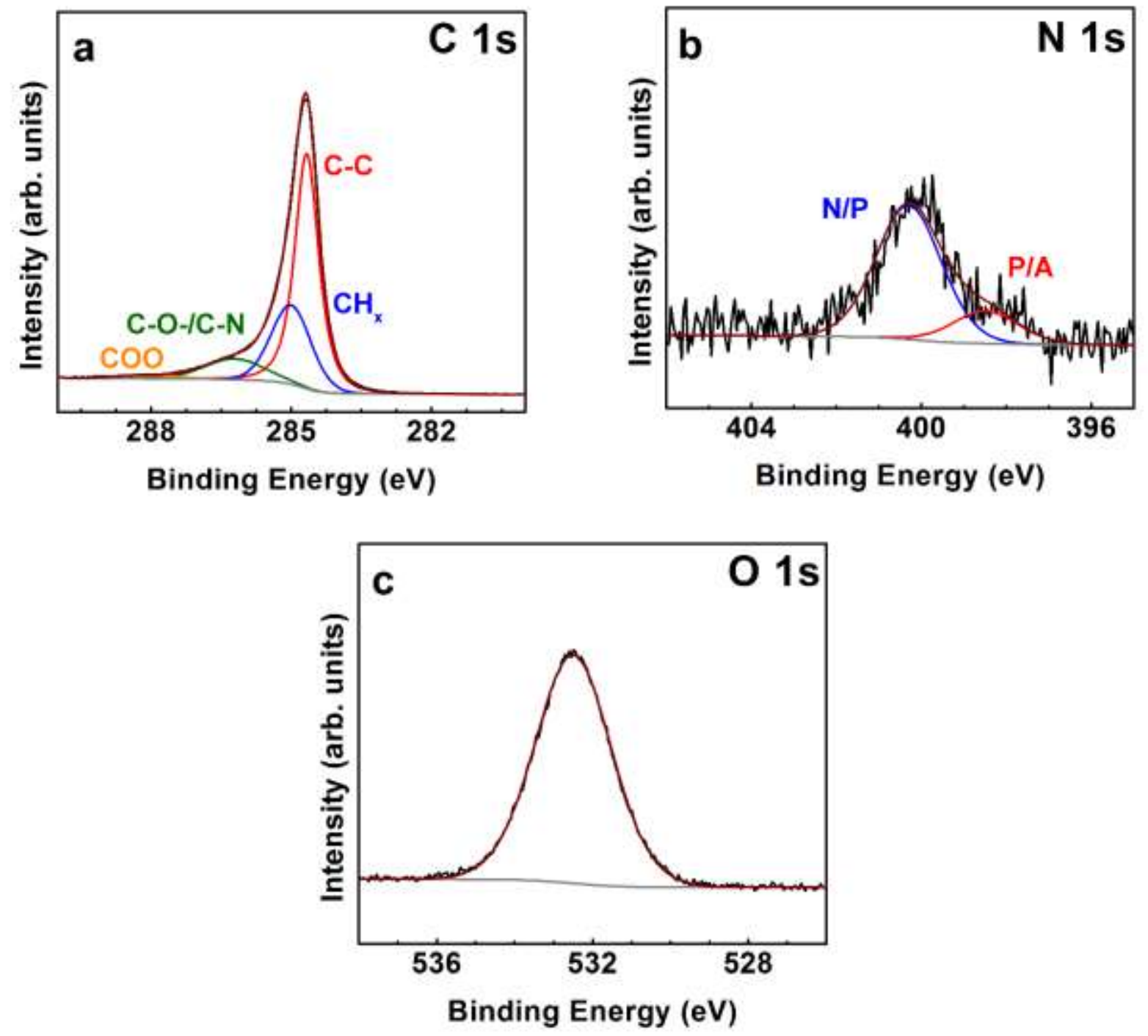

Figure 3 XPS spectra of $C 1 s, N$ 1s and $O$ 1s regions for AEG. 
Table 2: Elemental analysis of AEG obtained from XPS characterization of the survey spectra.

\begin{tabular}{|c|c|c|c|c|}
\hline Sample & C at.\% & N at.\% & O at.\% & Si at.\% \\
\hline AEG & $89.9 \pm 0.1$ & $0.5 \pm 0.1$ & $9.0 \pm 0.1$ & $0.6 \pm 0.1$ \\
\hline
\end{tabular}

To analyze the electrochemical properties and quantify the working potential windows of the AEG electrode material, cyclic voltammograms (CVs), in a $6 \mathrm{M} \mathrm{KOH}$ aqueous solution, in a threeelectrode configuration was primarily performed. Figure 4 (a) and (b) show the CV of the AEG electrode at a scan rate of $50 \mathrm{mV} \mathrm{s}^{-1}$. The $\mathrm{CV}$ of the AEG electrode is measured within a negative potential window of -1.2 to $0.0 \mathrm{~V}$ vs. $\mathrm{Ag} / \mathrm{AgCl}$ as well as within a positive voltage window of 0.0 to $1.0 \mathrm{~V}$ vs. $\mathrm{Ag} / \mathrm{AgCl}$. The $\mathrm{CV}$ curves show rectangular shape in both potential windows, which indicate a good current response behavior. Below $-1.0 \mathrm{~V}$ and above $0.9 \mathrm{~V}$, cathodic and anodic current leaps are observed which are indications of di-hydrogen and oxygen evolution as the potential approaches $-1 \mathrm{~V}$ and $0.9 \mathrm{~V}$. On the basis of these results, it is expected that the
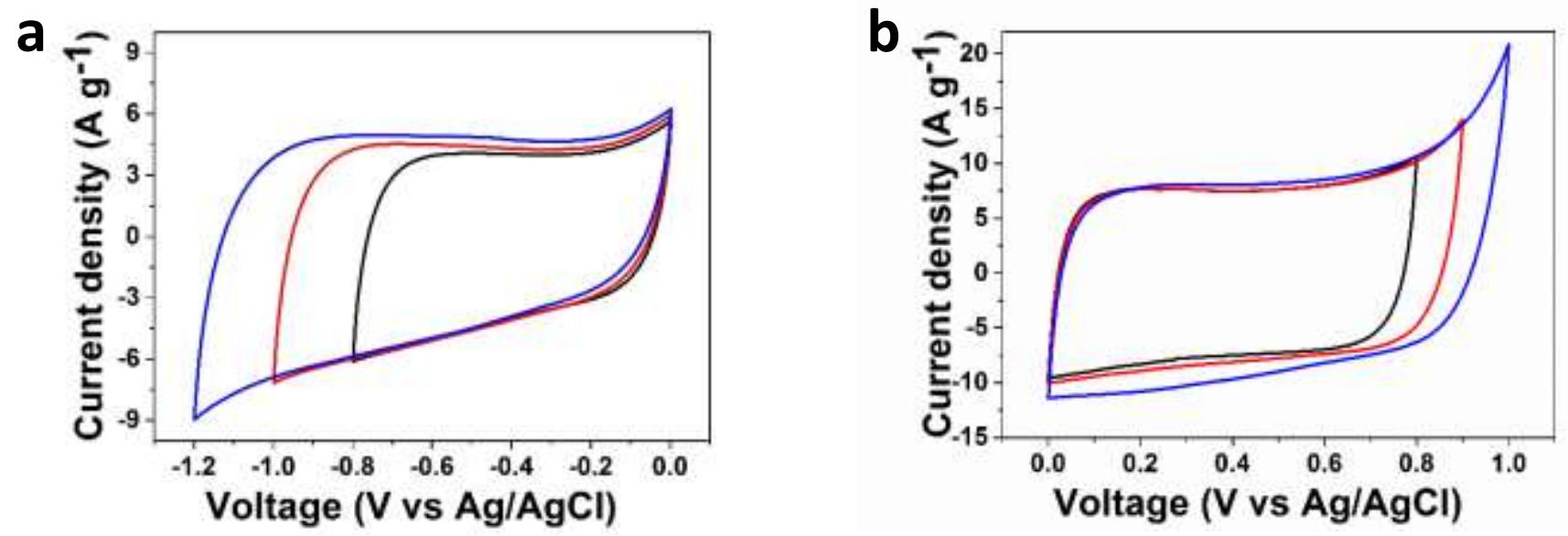

Figure 4 Three electrode $\mathrm{CV}$ measurements in $6 \mathrm{M} \mathrm{KOH}$ aqueous electrolyte at $50 \mathrm{mV} \mathrm{s}^{-1}$ at different potential windows in (a) the negative voltage range and (b) the positive voltage range 
operating symmetric two electrode cell voltage could be extended to about $1.9 \mathrm{~V}$ in $6 \mathrm{M} \mathrm{KOH}$ solution since the best potential windows for positive electrode can be up to $0.9 \mathrm{~V}$ and that of the negative one can be up to $-1.0 \mathrm{~V}$.

A two-electrode symmetric supercapacitor was fabricated to further test the electrochemical performance of the supercapacitor device based on the AEG electrode. Figure 5 (a) shows the combined $\mathrm{CV}$ in both the positive and negative voltage windows to the extended potential window of 2.4 V. The CV curves seem to still keep a rectangular shape with increasing total potential window, however, at about $\pm 1.2 \mathrm{~V}$ current leaps on both sides of the $\mathrm{CV}$ curves were observed. These current leaps correspond to the evolution of oxygen and hydrogen on both side of the electrode as mentioned above [30,31]. To avoid these phenomena, the working voltage of the symmetric cell was kept to $1.8 \mathrm{~V}$ (from -0.9 to $0.9 \mathrm{~V}$ ). At this voltage the $\mathrm{CV}$ curves maintained a symmetric reversible rectangular shape indicating ideal capacitive behavior and outstanding reversibility as shown in Figure 5 (b). The CV curves of the symmetric cell at different scan rates from 5 to $100 \mathrm{mV} \mathrm{s}^{-1}$ are shown in Figure 5 (b). The CV shapes does not change significantly even at high scan rate of $100 \mathrm{mV} \mathrm{s}^{-1}$, indicating rapid ions transportation and good rate capability. The broad peak at $\sim 0.6 \mathrm{~V}$ on the $\mathrm{CV}$ curves can be associated to the redox activities of nitrogen and oxygen in the matrix of the electrode material. The constant current charge-discharge $(C D)$ curves are shown in Figure 5 (c). Surprisingly, the CD curves exhibits a linear voltage-time function with non-symmetric triangular shape with longer discharge time compared to the charging time. This could be tentatively attributed to the presence of nitrogen and oxygen in the electrode materials which could promote faradaic reaction, influencing the discharge time. The corresponding electrode specific capacitance and 
Ragone plot (Figure 5 (d)) showing the energy density versus the power density of the symmetric supercapacitor are calculated from the CD curves according to the equations below $[32,33]:$

$C_{s p}=4 \times \mathrm{I} \Delta t / m \Delta V$

$E_{\text {max }}=0.5 C(\Delta V)^{2}=\left(C_{s p} \times \Delta V^{2}\right) / 28.8$

$P_{\max }=3.6 \times E_{\max } / \Delta t$

Where $C_{s p}$ is the specific capacitance $\left(\mathrm{F} \mathrm{g}^{-1}\right), \mathrm{E}_{\max }$, the maximum energy density $\left(\mathrm{Wh} \mathrm{kg}^{-1}\right), \mathrm{P}_{\max }$, the power density $\left(\mathrm{kW} \mathrm{kg}^{-1}\right), \mathrm{I}$ is the discharge current $(\mathrm{A}), \mathrm{m}$ is the total mass of the active material in both electrodes $(\mathrm{g}), \Delta \mathrm{t}$ is the discharge time $(\mathrm{s})$, and $\Delta \mathrm{V}$ is the applied potential $(\mathrm{V})$.

The device exhibits a specific capacitance of $337 \mathrm{~F} \mathrm{~g}^{-1}$ at a current density of $0.5 \mathrm{~A} \mathrm{~g}^{-1}$ and an outstanding energy density of $37.9 \mathrm{Wh} \mathrm{kg}^{-1}$ at a power density of $450 \mathrm{~W} \mathrm{~kg}^{-1}$ at the same current density. The energy density of AEG based symmetric supercapacitor is higher than those previously reported for carbon-based symmetric supercapacitors in aqueous electrolyte [34-36]. Table 3 compares the $C_{s p}, E_{\max }$ values obtained in this work with previous values reported.

Cycling test based on floating has been used to investigate the long-term stability of the symmetric device based on AEG. During ageing, a $10 \mathrm{~h}$ period of potentiostatic mode (called 'floating') was followed by five galvanostatic charge-discharge at $1 \mathrm{~A} \mathrm{~g}^{-1}$ and the specific capacitance value was estimated from the fifth discharge. The floating and galvanostatic 
Table 3 Performance comparison of AEG symmetric cell with previous reported electrodes

\begin{tabular}{|c|c|c|c|c|c|c|c|c|}
\hline Precursor & $\begin{array}{c}\text { Activation } \\
\text { agent }\end{array}$ & $\begin{array}{c}\mathrm{S}_{\mathrm{BET}} \\
\left(\mathrm{m}^{2} \mathrm{~g}^{-1}\right)\end{array}$ & $\begin{array}{l}\text { Potential } \\
\text { (V) }\end{array}$ & $\begin{array}{l}\text { Capacitance } \\
\qquad\left(\mathrm{Fg}^{-1}\right)\end{array}$ & Scan rate & Electrolyte & $\begin{array}{l}\text { Energy } \\
\left(\mathrm{W} \mathrm{h} \mathrm{kg}^{-1}\right)\end{array}$ & Ref. \\
\hline Coal tar pitch & $\mathrm{KOH}$ & 1003 & 1 & $224(2)$ & $0.1 \mathrm{~A} \mathrm{~g}^{-1}$ & $6 \mathrm{M} \mathrm{KOH}$ & 7.8 & [37] \\
\hline Poly-aniline (PANI) & - & 400 & 1 & $125(3)$ & $0.2 \mathrm{Ag}^{-1}$ & $6 \mathrm{M} \mathrm{KOH}$ & - & [38] \\
\hline polystyrene & $\mathrm{KOH}$ & 2350 & 1 & $258(3)$ & $5 \mathrm{mV} \mathrm{s}^{-1}$ & $6 \mathrm{M} \mathrm{KOH}$ & - & [39] \\
\hline $\begin{array}{l}\text { Polyvinyl alcohol/ } \\
\text { graphene }\end{array}$ & $\mathrm{KOH}$ & 2994 & 1.6 & $188(2)$ & $0.5 \mathrm{~A} \mathrm{~g}^{-1}$ & $6 \mathrm{M} \mathrm{KOH}$ & 16.7 & [40] \\
\hline Bamboo & $\mathrm{KOH}$ & 1472 & 1 & $301(3)$ & $0.1 \mathrm{Ag}^{-1}$ & $6 \mathrm{M} \mathrm{KOH}$ & & {$[41]$} \\
\hline Bamboo & $\mathrm{KOH}$ & 1472 & 3.5 & $146(2)$ & $0.2 \mathrm{~A} \mathrm{~g}^{-1}$ & EMIM TFSI & 6.1 & {$[41]$} \\
\hline 3D graphene & - & 3523 & 3.5 & $202(2)$ & $1 \mathrm{Ag}^{-1}$ & $\begin{array}{c}1 \mathrm{M} \\
\text { TEABF4/AN }\end{array}$ & 51 & [15] \\
\hline Graphite & $\begin{array}{c}\mathrm{HNO}_{3} / \mathrm{H}_{2} \mathrm{~S} \\
\mathrm{O}_{4}(1: 1)\end{array}$ & - & 2.5 & $1071(3)$ & - & $0.1 \mathrm{M} \mathrm{KOH}$ & - & {$[42]$} \\
\hline $\begin{array}{l}\text { Poly(vinylidene } \\
\text { chloride) (PVDC) }\end{array}$ & $\mathrm{KOH}$ & 2050 & 4 & $38(2)$ & $1 \mathrm{mV} \mathrm{s}^{-1}$ & $\begin{array}{c}1 \mathrm{M} \\
\mathrm{TEABF}_{4} \text { in } \mathrm{PC}\end{array}$ & - & [43] \\
\hline $\begin{array}{c}\text { Phenol- } \\
\text { formaldehyde } \\
\text { resin }\end{array}$ & $\mathrm{KOH}$ & 1902 & 1.3 & $105(2)$ & - & $1 \mathrm{M} \mathrm{H}_{2} \mathrm{SO}_{4}$ & - & [44] \\
\hline Polypyrrole (PPy) & $\mathrm{KOH}$ & 3432 & 2.3 & $290(2)$ & $0.1 \mathrm{Ag}^{-1}$ & $\mathrm{EMImBF}_{4}$ & - & {$[45]$} \\
\hline $\begin{array}{l}\text { Expanded } \\
\text { graphite }\end{array}$ & $\mathrm{KOH}$ & 457 & 1.8 & 337 & $0.5 \mathrm{Ag}^{-1}$ & $6 \mathrm{M} \mathrm{KOH}$ & 37.9 & $\begin{array}{l}\text { This } \\
\text { work- }\end{array}$ \\
\hline
\end{tabular}

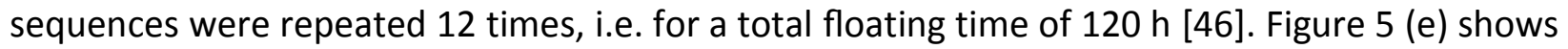
the stability during voltage-holding over $120 \mathrm{~h}$. Floating has a significant impact on the specific capacitance which rapidly increases and decreases during the first $20 \mathrm{~h}$ of ageing, before stabilizing at a constant value throughout the remaining ageing time. The increase is due to the insertion of ions into the matrix of the electrode at the initial stage of the holding, while the decrease could be related to partial removal of surface functional groups. Only $10 \%$ of capacitance loss was observed during the first $20 \mathrm{~h}$ of ageing. The excellent stability of the AEG electrode material showed that this device can be charged and discharged with little degree of degradation. Figure 5 (f) shows the CV curves at a scan rate of $10 \mathrm{mV} \mathrm{s}^{-1}$ before and after 

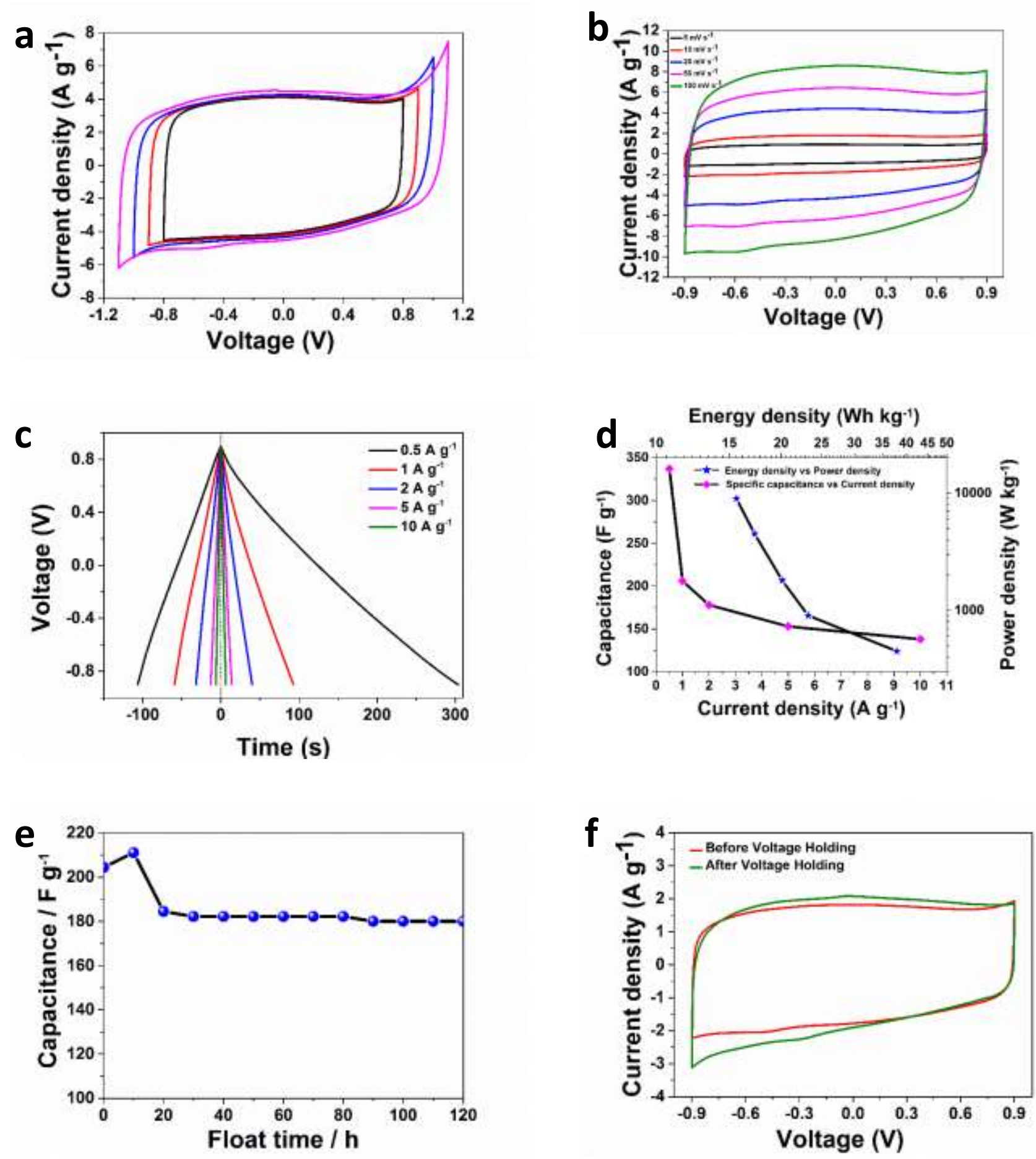

Figure 5 (a) CV curves at $50 \mathrm{mV} \mathrm{s}^{-1}$ at different voltage windows, (b) CV curves at scan rates from 5 to $100 \mathrm{mV} \mathrm{s}^{-1}$, (c) The galvanostatic charge/discharge curves from 0.5 to $10 \mathrm{~A} \mathrm{~g}^{-1}$, (d) Ragone plot and the specific capacitance as function of the current density, (e) voltage holding vs. capacitance at a constant current density of $1 \mathrm{~A} \mathrm{~g}^{-1}$, and (f) $\mathrm{CV}$ curves at scan rate of $10 \mathrm{mV} \mathrm{s}^{-1}$ before and after cycling of symmetric AEG two electrode cell, respectively. 
voltage holding. The cell showed no significant degradation with only a small current leap at the negative electrode. Overall, the CV indicates that there was very little decay in the capacitive performance of the cell, confirming the result obtained in Figure 5 (e).

EIS analysis is crucial to investigate the behavior of the electrodes. The impedance measurement was taken in an open circuit potential, in the frequency range of $100 \mathrm{kHz}-0.01 \mathrm{~Hz}$. The Nyquist impedance plot is presented in Figure 6 (a) which features a small arc in the high and middle frequency region indicating charge transfer resistance $\left(R_{C T}\right)$, and a nearly vertical line in the low frequency region, indicating ideal capacitive behavior and good electrical conductivity of the AEG electrode material. The intersection with the real $Z^{\prime}$ axis from Nyquist is the solution resistance $\left(R_{S}\right)$ which includes the total resistance of the ionic resistance of electrolyte, the intrinsic resistance of the active materials and the contact resistance at the interface between the active electrode material and current collector [47]. From the Figure, the $R_{S}$ and $R_{C T}$ values of the device are $0.4 \Omega$ and $1.6 \Omega$, respectively. The fitting of the Nyquist plot was performed with a fitting program ZFIT/EC-Lab version 10.40 using the equivalent circuit shown as inset of Figure 6 (a). The fitting is also shown in Figure 6 (a). In the equivalent circuit, the solution resistance $\left(R_{s}\right)$ is connected in series with a constant phase element $Q$, which is connected in parallel with the charge transfer resistance $\left(R_{C T}\right)$. The transition from high-low frequency region is modelled by Warburg diffusion element and represented by Which is in series with $\mathrm{R}_{\mathrm{CT}}$. Ideally, at very low frequencies, an ideal polarizable capacitive electrode with the mass capacitance $\left(C_{L}\right)$ should give rise to a straight line parallel to the imaginary axis, However, from the Nyquist plot in Figure 6 (a) there is a divergence from this ideal behavior. This divergence is attributed to the existence of a resistive element associated to $C_{L}$. This 
resistance is denoted as leakage resistance $R_{L}$ and is in parallel with $C_{L}$. Table 5 below summarizes all the parameters obtained from the fitting. The result indicates an optimized minimization of experimental data with the design of the cell with an error of $0.03 . X^{2}$ represents the criterion for minimization of the fit. $\mathrm{X} / \sqrt{N}$ where $\mathrm{N}$ is the number of data points, is a normalized expression of $\mathrm{X}^{2}$, whose value is independent to the number of points and is represented as the error. EIS measurements were made after voltage holding and the result is
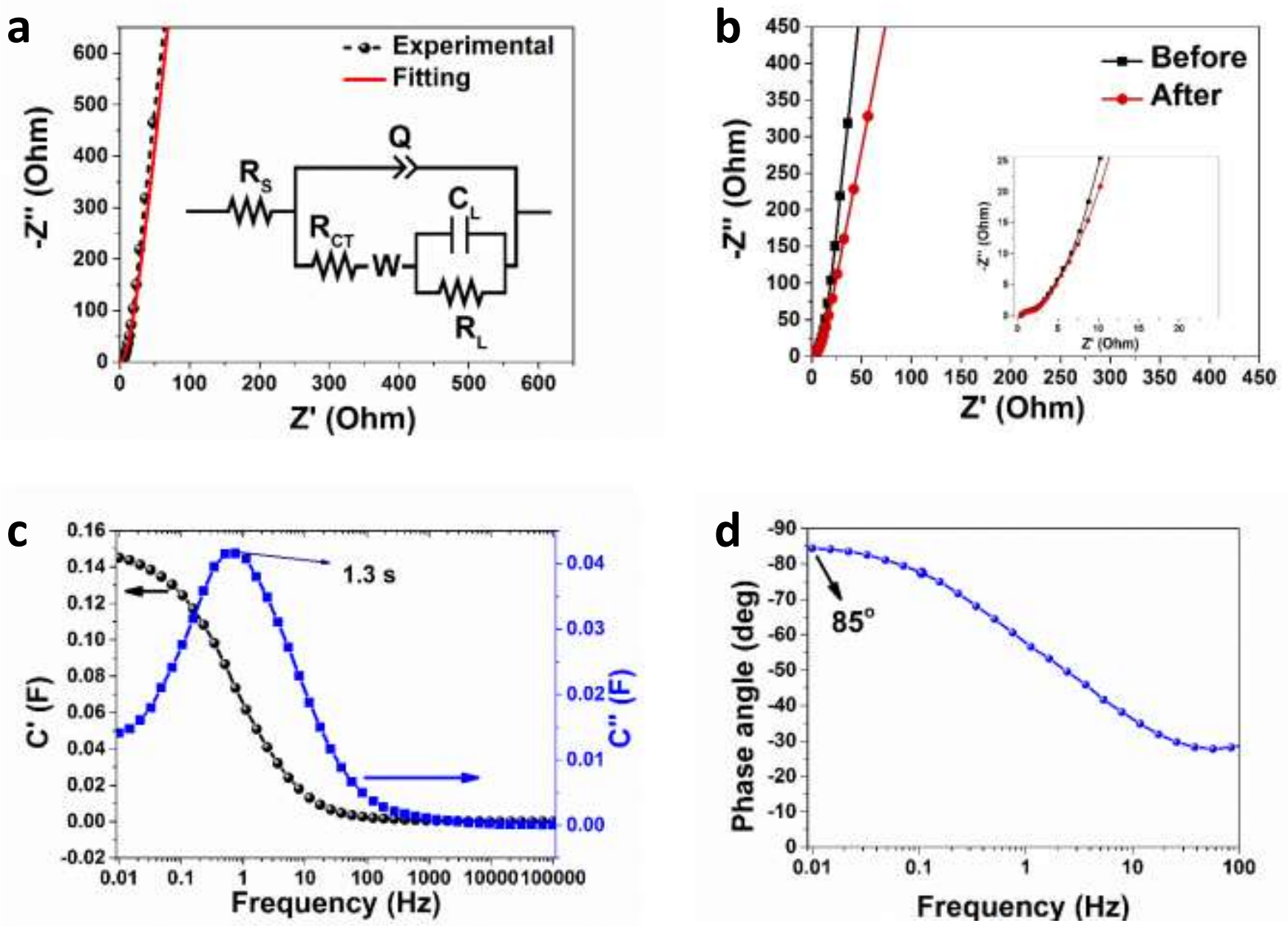

Figure 6 (a) EIS plot and fitting curve, (b) EIS before and after cycling, (c) the real and the imaginary part of the cells capacitance against frequency, (d) the phase angle versus frequency in $6 \mathrm{M} \mathrm{KOH}$ aqueous electrolytes of symmetric AEG two electrode cell respectively. 
presented in Figure 6 (b). The result shows that there was no much deviation to the initial Nyquist plot confirming that indeed only very little degradation of the electrode material occurred.

The real and imaginary parts of the capacitance of the cell as a function of the frequency are shown in Figure 6 (c). $C^{\prime}$ represents the real accessible capacitance of the cell at the corresponding frequency $(0.01 \mathrm{~Hz})$, representing the deliverable capacitance which is $0.145 \mathrm{~F}$. The evolution of $C^{\prime \prime}$ which defines the transition frequency between a pure capacitive and a pure resistive behavior is also shown in the figure which also represents the energy loss due to the irreversible process of the electrodes. C" is also used to define the transition between pure capacitive and pure resistive behavior of the AEG sample [48]. From the figure, $C^{\prime \prime}$ as a function of frequency shows a peak which appears at a maximum frequency of $0.75 \mathrm{~Hz}$ defining a relaxation time of $\sim 1.3 \mathrm{~s}$ obtained from $\tau=1 / \omega_{\max }=1 /\left(2 \pi f_{\max }\right)$. This value indicates that the full capacitance of the cell can be reached within a fast charging time of $1.3 \mathrm{~s}$. Finally Figure 6 (d) presents the phase angle as a function of frequency. The phase angle for the electrodes is about $\sim-84.5^{\circ}$, very close to $-90^{\circ}$ which defines ideal capacitive response.

\section{CONCLUSION}

In summary, novel carbon nanosheets derived from expanded graphite was synthesized. The produced AEG material possesses a sheet-like morphology with presence of small amount of oxygen and nitrogen as revealed by XPS. An improved SSA of $457 \mathrm{~m}^{2} \mathrm{~g}^{-1}$ compared to the that of EG results in high specific capacitance of $337 \mathrm{~F} \mathrm{~g}^{-1}$, high energy density of $37.9 \mathrm{Wh} \mathrm{kg}^{-1}$ and power density of $450 \mathrm{~W} \mathrm{~kg}^{-1}$ at $0.5 \mathrm{~A} \mathrm{~g}^{-1}$ with excellent rate capability in $6 \mathrm{M} \mathrm{KOH}$ aqueous 
electrolyte. No significant degradation or capacitance loss of the supercapacitor cell was observed after $120 \mathrm{~h}$ of floating test. These results suggest that the AEG material has great potential in high performance energy storage device applications and is also expected to be useful to the broader scientific community on electrochemical capacitors if fully explored.

\section{ACKNOWLEDGEMENT}

This work is based upon research supported by the South African Research Chairs Initiative (SARChi) in Carbon Technology and Materials of the Department of Science and Technology (DST) and the National Research Foundation (NRF). Any opinions, findings and conclusions or recommendations expressed in this work are those of authors, and the NRF and the DST do not accept any liability with regard thereto. F. Barzegar, M. J. Madito and D. Y. Momodu acknowledge financial support from the University of Pretoria and the NRF for their PhD bursaries. A. Bello acknowledge the University of Pretoria's financial support for their Postdoctoral fellowship.

\section{REFERENCES}

[1] J. Ding, H. Wang, Z. Li, K. Cui, D. Karpuzov, X. Tan, et al., Peanut shell hybrid sodium ion capacitor with extreme energy-power rivals lithium ion capacitors, Energy Environ. Sci. 8 (2015) 941-955.

[2] X. Peng, L. Peng, C. Wu, Y. Xie, Two dimensional nanomaterials for flexible supercapacitors., Chem. Soc. Rev. 43 (2014) 3303-23.

[3] H. Sun, L. Cao, L. Lu, Bacteria promoted hierarchical carbon materials for high-performance supercapacitor, Energy Environ. Sci. 5 (2012) 6206. 
[4] P. Simon, Y. Gogotsi, Materials for electrochemical capacitors, Nat. Mater. 7 (2008) 845-854.

[5] J. Pu, F. Cui, S. Chu, T. Wang, E. Sheng, Z. Wang, Preparation and Electrochemical Characterization of Hollow Hexagonal NiCo 2 S 4 Nanoplates as Pseudocapacitor Materials, ACS Sustain. Chem. Eng. 2 (2014) 809-815.

[6] H. Jiang, P.S. Lee, C. Li, 3D carbon based nanostructures for advanced supercapacitors, Energy Environ. Sci. 6 (2013) 41-53.

[7] H. Wang, Z. Xu, A. Kohandehghan, Z. Li, K. Cui, X. Tan, et al., Interconnected carbon nanosheets derived from hemp for ultrafast supercapacitors with high energy., ACS Nano. 7 (2013) 5131-41.

[8] D. Higgins, Z. Chen, D.U. Lee, Z. Chen, Activated and nitrogen-doped exfoliated graphene as air electrodes for metal-air battery applications, J. Mater. Chem. A. 1 (2013) 2639.

[9] T. Brousse, D. Belanger, J.W. Long, To Be or Not To Be Pseudocapacitive?, J. Electrochem. Soc. 162 (2015) A5185-A5189.

[10] V. Presser, M. Heon, Y. Gogotsi, Carbide-Derived Carbons - From Porous Networks to Nanotubes and Graphene, Adv. Funct. Mater. 21 (2011) 810-833.

[11] Y. Gao, Y.S. Zhou, M. Qian, X.N. He, J. Redepenning, P. Goodman, et al., Chemical activation of carbon nano-onions for high-rate supercapacitor electrodes, Carbon N. Y. 51 (2013) 52-58.

[12] E. lyyamperumal, S. Wang, L. Dai, Vertically aligned BCN nanotubes with high capacitance., ACS Nano. 6 (2012) 5259-65.

[13] L.L. Zhang, R. Zhou, X.S. Zhao, Graphene-based materials as supercapacitor electrodes, J. Mater. Chem. 20 (2010) 5983-5992.

[14] X. Li, B. Wei, Supercapacitors based on nanostructured carbon, Nano Energy. 2 (2013) 159-173.

[15] L. Zhang, F. Zhang, X. Yang, G. Long, Y. Wu, T. Zhang, et al., Porous 3D graphene-based bulk materials with exceptional high surface area and excellent conductivity for supercapacitors, Sci. Rep. 3 (2013) 1408.

[16] L. Zhang, X. Yang, F. Zhang, G. Long, T. Zhang, K. Leng, et al., Controlling the effective surface area and pore size distribution of sp2 carbon materials and their impact on the capacitance performance of these materials., J. Am. Chem. Soc. 135 (2013) 5921-9.

[17] A. Bello, F. Barzegar, D. Momodu, F. Taghizadeh, M. Fabiane, J. Dangbegnon, et al., Morphological characterization and impedance spectroscopy study of porous 3D carbons based on graphene foamPVA/phenol-formaldehyde resin composite as an electrode material for supercapacitors, RSC Adv. 4 (2014) 39066-39072. 
[18] L. Dong, Z. Chen, D. Yang, H. Lu, Hierarchically structured graphene-based supercapacitor electrodes, RSC Adv. 3 (2013) 21183.

[19] Y. Ito, Y. Tanabe, H.-J. Qiu, K. Sugawara, S. Heguri, N.H. Tu, et al., High-Quality Three-Dimensional Nanoporous Graphene, Angew. Chemie. 126 (2014) 4922-4926.

[20] H. Aoki, M. S. Dresselhaus, eds., Physics of Graphene, Springer International Publishing, Cham, 2014.

[21] Y. Wang, D.C. Alsmeyer, R.L. McCreery, Raman spectroscopy of carbon materials: Structural basis of observed spectra, Chem. Mater. 2 (1990) 557-563.

[22] M. Cardona, G. Güntherodt, eds., Light Scattering in Solids III, Springer Berlin Heidelberg, Berlin, Heidelberg, 1982.

[23] A. Cuesta, P. Dhamelincourt, J. Laureyns, A. Martínez-Alonso, J.M.D. Tascón, Raman microprobe studies on carbon materials, Carbon N. Y. 32 (1994) 1523-1532.

[24] T. Jawhari, A. Roid, J. Casado, Raman spectroscopic characterization of some commercially available carbon black materials, Carbon N. Y. 33 (1995) 1561-1565.

[25] S. Sze, Raman spectroscopic characterization of carbonaceous aerosols, Atmos. Environ. 35 (2001) 561568.

[26] B. Dippel, H. Jander, J. Heintzenberg, NIR FT Raman spectroscopic study of flame soot, Phys. Chem. Chem. Phys. 1 (1999) 4707-4712.

[27] A. Sadezky, H. Muckenhuber, H. Grothe, R. Niessner, U. Pöschl, Raman microspectroscopy of soot and related carbonaceous materials: Spectral analysis and structural information, Carbon N. Y. 43 (2005) 17311742.

[28] A.P. Terzyk, The influence of activated carbon surface chemical composition on the adsorption of acetaminophen (paracetamol) in vitro, Colloids Surfaces A Physicochem. Eng. Asp. 177 (2001) 23-45.

[29] R.J.J. Jansen, H. van Bekkum, XPS of nitrogen-containing functional groups on activated carbon, Carbon N. Y. 33 (1995) 1021-1027.

[30] M.P. Bichat, E. Raymundo-Piñero, F. Béguin, High voltage supercapacitor built with seaweed carbons in neutral aqueous electrolyte, Carbon N. Y. 48 (2010) 4351-4361.

[31] L. Demarconnay, E. Raymundo-Piñero, F. Béguin, A symmetric carbon/carbon supercapacitor operating at $1.6 \mathrm{~V}$ by using a neutral aqueous solution, Electrochem. Commun. 12 (2010) 1275-1278. 
[32] M.D. Stoller, R.S. Ruoff, Best practice methods for determining an electrode material's performance for ultracapacitors, Energy Environ. Sci. 3 (2010) 1294-1301.

[33] Y. Gogotsi, P. Simon, True performance metrics in electrochemical energy storage, Science. 334 (2011) 917-918.

[34] M. Sevilla, W. Gu, C. Falco, M.M. Titirici, A.B. Fuertes, G. Yushin, Hydrothermal synthesis of microalgaederived microporous carbons for electrochemical capacitors, J. Power Sources. 267 (2014) 26-32.

[35] S. Shivakumara, B. Kishore, T.R. Penki, N. Munichandraiah, Symmetric supercapacitor based on partially exfoliated and reduced graphite oxide in neutral aqueous electrolyte, Solid State Commun. 199 (2014) 2632.

[36] Q. Gao, L. Demarconnay, E. Raymundo-Piñero, F. Béguin, Exploring the large voltage range of carbon/carbon supercapacitors in aqueous lithium sulfate electrolyte, Energy Environ. Sci. 5 (2012) 9611.

[37] X. He, R. Li, J. Qiu, K. Xie, P. Ling, M. Yu, et al., Synthesis of mesoporous carbons for supercapacitors from coal tar pitch by coupling microwave-assisted $\mathrm{KOH}$ activation with a MgO template, Carbon N. Y. 50 (2012) 4911-4921.

[38] K.-S. Kim, S.-J. Park, Easy synthesis of polyaniline-based mesoporous carbons and their high electrochemical performance, Microporous Mesoporous Mater. 163 (2012) 140-146.

[39] S.-J. Han, Y.-H. Kim, K.-S. Kim, S.-J. Park, A study on high electrochemical capacitance of ion exchange resinbased activated carbons for supercapacitor, Curr. Appl. Phys. 12 (2012) 1039-1044.

[40] F. Barzegar, A. Bello, O.O. Fashedemi, J.K. Dangbegnon, D.Y. Momodu, F. Taghizadeh, et al., Synthesis of 3D porous carbon based on cheap polymers and graphene foam for high-performance electrochemical capacitors, Electrochim. Acta. 180 (2015) 442-450.

[41] W. Tian, Q. Gao, Y. Tan, K. Yang, L. Zhu, C. Yang, et al., Bio-inspired beehive-like hierarchical nanoporous carbon derived from bamboo-based industrial by-product as a high performance supercapacitor electrode material, J. Mater. Chem. A. 3 (2015) 5656-5664.

[42] R. Nandhini, P.A. Mini, B. Avinash, S.V. Nair, K.R.V. Subramanian, Supercapacitor electrodes using nanoscale activated carbon from graphite by ball milling, Mater. Lett. 87 (2012) 165-168.

[43] Y.. Kim, Y. Horie, S. Ozaki, Y. Matsuzawa, H. Suezaki, C. Kim, et al., Correlation between the pore and solvated ion size on capacitance uptake of PVDC-based carbons, Carbon N. Y. 42 (2004) 1491-1500.

[44] H. Teng, Y.-J. Chang, C.-T. Hsieh, Performance of electric double-layer capacitors using carbons prepared from phenol-formaldehyde resins by KOH etching, Carbon N. Y. 39 (2001) 1981-1987. 
[45] L. Wei, M. Sevilla, A.B. Fuertes, R. Mokaya, G. Yushin, Polypyrrole-Derived Activated Carbons for HighPerformance Electrical Double-Layer Capacitors with Ionic Liquid Electrolyte, Adv. Funct. Mater. 22 (2012) 827-834.

[46] P. Ratajczak, K. Jurewicz, F. Béguin, Factors contributing to ageing of high voltage carbon/carbon supercapacitors in salt aqueous electrolyte, J. Appl. Electrochem. 44 (2013) 475-480. doi:10.1007/s10800013-0644-0.

[47] J. Luo, H.D. Jang, J. Huang, Effect of sheet morphology on the scalability of graphene-based ultracapacitors., ACS Nano. 7 (2013) 1464-71.

[48] P.L. Taberna, P. Simon, J.-F.F. Fauvarque, Electrochemical Characteristics and Impedance Spectroscopy Studies of Carbon-Carbon Supercapacitors, J. Electrochem. Soc. 150 (2003) A292-300. 